\title{
KEEFEKTIFAN MODEL PEMBELAJARAN TGT (TEAM GAMES TOURNAMENT) BERBANTU MEDIA PAPAN PUTAR UNTUK MENINGKATKAN PRESTASI BELAJAR SISWA KELAS IV PEMBELAJARAN TEMATIK
}

\author{
Putri Indah Wahyuningsih ${ }^{1}$, Nur Khoiri ${ }^{2}$, Ervina Eka Subekti ${ }^{3}$ \\ ${ }^{1,2,3}$ PGSD Fakultas IImu Pendidikan Universitas PGRI Semarang \\ e-mail: putriindah939@gmail.com
}

\begin{abstract}
ABSTRAK
Untuk mengetahui keefektifan model pembelajaran TGT (Team Games Tournament) berbantu media papan putar untuk meningkatkan prestasi belajar siswa kelas IV pembelajaran tematik di SD Negeri Rejosari 03. Teknik sampling yang digunakan dalam penelitian ini adalah jenis Probability Sampling dengan teknik Simple Random Sampling. Simple Random Sampling, dikatakan simple (sederhana) karena pengambilan anggota sampel dari populasi dilakukan secara acak tanpa memperlihatkan strata yang ada dalam populsi itu. Desain Penelitian ini menggunakan desain True Experimental Designs dengan bentuk Pretest - Posttest Control Group Design. Dalam bentuk desain ini terdapat dua kelompok yang dipilih secara acak (random), kemudian diberi Pretest untuk mengetahui keadaan awal adakah perbedaan antara kelompok eksperimen dan kelompok kontrol. Hasil Pretest yang baik bila nilai kelompok eksperimen tidak berbeda secara signifikan. Pengaruh perlakuan adalah $(\mathrm{O} 2-\mathrm{O} 1)-(\mathrm{O} 4-\mathrm{O} 3)$.
\end{abstract}

Kata Kunci : Model Pembelajaran TGT, Media Papan Putar, Prestasi Belajar..

\begin{abstract}
To determine the effectiveness of the TGT (Team Games Tournament) learning model assisted by rotating media to improve the learning achievement of fourth grade students in thematic learning at SD Negeri Rejosari 03. The sampling technique used in this study is the type of Probability Sampling with Simple Random Sampling technique. Simple Random Sampling is said to be simple because the taking of sample members from the population is done randomly without showing the strata in that population. This research design uses the design of True Experimental Designs in the form of Pretest - Posttest Control Group Design. In this form of design there are two groups randomly selected, then given the Pretest to find out the initial state is there a difference between the experimental group and the control group. Pretest results are good if the value of the experimental group is not significantly different. The effect of treatment is (O2 - O1) - (O4 - O3).
\end{abstract}

Keyword: TGT Learning Model, Media Play Board, Learning Achievement. 


\section{Pendahuluan}

Pendidikan merupakan salah satu aspek yang sangat penting bagi manusia, karena pendidikan bisa dikatakan sebagai kebutuhan dasar manusia pada saat ini. Pada hakikatnya siswa tidak sekedar sebagai penerima ilmu melainkan siswa juga diharapkan mempunyai keterampilan dan skill dalam menghadapi masa depan. Sistem pendidikan yang baik akan melahirkan generasi bangsa yang cerdas dan baik pula. Generasi bangsa yang cerdas ialah modal awal bagi suatu bangsa dalam melakukan pembangunan ke arah yang lebih baik dalam usaha mencapai pembangunan nasional (Candra, 2017). Pembangunan yang dilakukan oleh suatu bangsa menandakan bahwa bangsa tersebut merupakan bangsa yang bermartabat karena selalu melakukan peningkatan kualitas dan beradaptasi dengan peradaban zaman.

Kebijakan umum Pengembangan Pembangun Pendidikan dan Pembangunan pada Nawacita yang tertuang dalam RPJMN 2015-2019 Menyatakan bahwa, pendidikan harus bisa meningkatkan kualitas hidup manusia Indonesia dan melakukan revolusi kehidupan bangsa. Kualitas kehidupan bangsa dapat ditingkatkan melalui sektor pendidikan, RPJMN 2010 -2014 menyatakan bahwa sektor pendidikan dapat memperbaiki penataan kurikulum dan penataan kurikulum metodelogi pembelajaran. Oleh karena, itu dilakukan perbaikan kurikulum 2013. Kurikulum 2013 diperbaiki tahun 2016 pada bagian KI-KD dan Kurikulum 2013 tersebut, saat ini merupakan kurikulum yang berlaku secara nasional. Upaya ini dilakukan untuk percepatan pelaksanaan pembangunan nasional. Hal ini diperkuat INPRES No. 1 Tahun 2010 bahwa percepatan pelaksanaan prioritas pembangunan nasional yaitu penyempurnaan kurikulum dan metode pembelajaran aktif berdasarkan nilai-nilai Budaya bangsa untuk membentuk daya saing dan karakter bangsa.

Kecakapan Abad 21 yang dikembangkan melalui Kurikulum 2013 yaitu kualitas karakter dan kompetensi. Hal tersebut dapat Dicapai melalui Intrakurikuler dan Kokurikuler, ekstrakurikuler, dan budaya sekolah didukung dengan bahan ajar dalam bentuk fisik dan digital, serta sarana prasarana. Nana Sudjana Tahun (2005) menyatakan bahwa Kurikulum merupakan niat \& harapan yang dituangkan kedalam bentuk rencana maupun program pendidikan yang dilaksanakan oleh para pendidik di sekolah. Kurikulum sebagai niat \& rencana, sedangkan pelaksaannya adalah proses belajar mengajar. Yang terlibat didalam proses tersebut yaitu pendidik dan peserta didik.

Pembelajaran kooperatif adalah suatu metode belajar yang mengkondisikan siswa belajar, bekerjasama dan aktif berinteraksi dalam kelompok-kelompok kecil yang memenuhi lima unsur pokok pembelajaran kooperatif. Metode pembelajaran kooperatif, para siswa akan duduk bersama dalam kelompok yang beranggotakan empat orang untuk menguasai materi yang disampaikan oleh guru (Slavin, 2010). Lima unsur pokok tersebut adalah saling kebergantungan positif, tanggung jawab individual, interaksi personal, keahlian bekerjasama dan evaluasi proses kelompok. Kelompok pada pembelajaran kooperatif hanya terdiri dari empat sampai enam orang siswa. Salah satu tipe model cooperative adalah teams games tournament (TGT) yang sangat menekankan pada pentingnya interaksi dalam tim" (Marianti :2017).

Menurut Kiranawati (2007) pembelajaran kooperatif model TGT (Team Games Tournament) adalah salah satu tipe atau model pembelajaran kooperatif yang mudah diterapkan, melibatkan aktivitas seluruh siswa tanpa harus ada perbedaan status, melibatkan peran siswa sebagai tutor sebaya dan mengandung unsur permainan dan reinforcement. Purwandari (2017) mengatakan bahwa "dengan menerapkan model pembelajaran TGT di kelas diharapkan dapat menghilangkan anggapan siswa tentang pelajaran yang membosankan" Sudimahayasa (2015) mngatakan bahwa TGT menambahkan dimensi kegembiraan yang diperoleh dari penggunaan permainan. Menurut Sunanna (2018) menyatakan bahwa model pembelajaran ini dapat meningkatkan kinerja pengajaran guru dan prestasi belajar siswa, serta merupakan suatu kiat, petunjuk, strategi, dan seluruh proses belajar yang dapat mempertajam pemahaman daya ingat, serta belajar sebagai proses yang menyenangkan dan bermakna. Pada penerapan model ini dibutuhkan penguasaan materi yang baik oleh seorang guru dan mampu memfasilitasi siswa dalam 
memahami dan menerapkan konsep ke dalam suatu contoh dengan baik dan tepat. Model pembelajaran kooperatif tipe Teams Games Tournament (TGT) salah satu tipe atau model pembelajaran kooperatif yang mudah diterapkan, melibatkan aktivitas seluruh siswa tanpa harus ada perbedaan status, melibatkan peran siswa sebagai tutor sebaya dan mengandung unsur permainan dan penguatan (Yudianto, 2014). Keunggulan pembelajaran tipe TGT adalah adanya turnamen akademik dalam proses pembelajaran. Dimana setiap anggota kelompok mewakili kelompoknya untuk melakukan turnamen (Tarigan, 2012).

Aktivitas belajar dengan permainan yang dirancang dalam pembelajaran kooperatif model TGT memungkinkan peserta didik dapat belajar lebih rileks disamping menumbuhkan tanggung jawab, kerjasama, persaingan sehat dan keterlibatan belajar. Pemakaian Media Papan Putar dengan model pembelajaran Team Games Tournamnet ( TGT ) dimaksudkan agar peserta didik lebih aktif dan tertarik saat pembelajaran. Pendekatan yang digunakan adalah dengan membentuk kelompok - kelompok kecil agar siswa dapat bekerjasama dengan kelompoknya dengan masing - masing tugas yang terstruktur.

Menurut Zainal (2016: 12) kata "prestasi" berasal dari bahasa Belanda yaitu prestatie yang artinya "hasil usaha". Istilah "prestasi belajar" (achivement) berbeda dengan hasil belajar (learning aoutcome). "Prestasi belajar pada umumnya berkenaan dengan aspek pengetahuan, sedangkan hasil belajar meliputi aspek watak pembentukan peserta didik. Tingkat keberhasilan peserta didik dalam prestasi belajar diukur dari segi kognitifnya.

Berdasarkan uraian di atas, maka perlu dilakukan penelitian untuk menguji "Keefektifan Model Pembelajaran TGT (Team Games Tournamnet ) Berbantu Media Papan Putar Untuk meningkatkan Prestasi Belajar Siswa Kelas IV Pembelajaran Tematik di SD Negeri Rejosari 03"

\section{Metode}

Peneliti melakukan penelitian di SDN Rejosari 03 Kabupaten Semarang yang beralamatkan di Dusun Galangan Rt.01 Rw.06, Desa Rejosari, Kecamatan Bancak, Kabupaten Semarang, Jawa Tengah 50772. Penelitian dilakukan pada Semester Gasal Tahun Ajaran 2018/2019. Variabel penelitian adalah segala sesuatu yang berbentuk apa saja yang ditetapkan oleh peneliti untuk dipelajari sehingga diperoleh informasi tentang hal tersebut, kemudian ditarik kesimpulan. Sugiyono (2011:38).Data dalam penelitian ini digunakan untuk mengetahui keefektifan model pembelajaran TGT (Team Games Tournament) berbantu media Papan Putar pada hasil belajar siswa kelas IV Materi Tematik SD Negeri Rejosari 03 Kecamatan Bancak Kabupaten Semarang dengan jumlah 22 siswa. Teknik pengumpulan data yang digunakan dalam penelitian adalah Tes dan Dokumentasi. Tes dilakukan dalam rangka mengukur hasil belajar siswa setelah proses pembelajaran menggunakan model pembelajaran TGT (Team Games Tournament) berbantu media Papan Putar. Metode tes yang digunakan untuk memperoleh nilai hasil belajar Materi dengan instrumen berupa soal-soal tes yang terdiri dari butir-butir tes. Tes tersebut adalah jenis tes tertulis dengan bentuk pilihan ganda yang akan diberikan kepada siswa. Dalam Tes ini terdapat dua tes yang akan didberikan kepada siswa yaitu : 1) Pretest yaitu tes yang diberikan kepada siswa dalam bentuk pilihan ganda sebelum diberi perlakuan atau sebelum pembelajaran dilaksanakan,2) Posttest yaitu tes yang diberikan kepada siswa dalam bentuk pililhan ganda setelah diberi perlakuan atau setelah pembelajaran selesai. Dokumentasi berupa arsip nilai siswa, foto-foto pelaksanaan proses pembelajaran yang dilakukan di SD Negeri Rejosari 03. Uji yang digunakan dalam penelitian ini yaitu: Uji Normalitas, Uji Homogenitas, Uji t, Uji Hipotesis..

\section{Hasil dan Pembahasan}

Hasil temuan empiris dilakukkan melalui wawancara dan observasi dengan guru kelas IV SD Negeri Rejosari 03 yaitu Ibu Rusminah S.Pd bahwa terdapat kendala dalam proses pembelajaran. Kendala meliputi beberapa hal yaitu : 1) Sarana dan prasarana sekolah yang kurang memadahi untuk proses pembelajaran. 2) Siswa masih kurang aktif 
dalam pembelajaran. 3) Model dan media pembelajaran yang digunakan guru belum variatif. Maka solusi yang dapat diberikan untuk mengatasi kendala di atas, menggunakan model pembelajaran yang dapat membuat siswa aktif, kreatif dan inovatif.

Salah satu solusinya, guru dapat memakai model pembelajaran koorperatif yang dikemas dengan permainan. Salah satu model coorperative learning yaitu Team Games Tournamnet (TGT). Alasan memilih Model Team Games Tournament ( TGT ) karena model ini tidak hanya belajar kelompok melainkan juga adanya Games dan Tournament sehingga, siswa akan lebih tertarik daripada hanya belajar kelompok. Selain itu, di dalam model pembelajaran TGT terdapat nilai karakter yaitu sifat kepemimpinan dan kolaborasi yang menyebabkan peserta didik memiliki daya saing antar kelompok. Dengan adanya Tournament tersebut siswa akan merasa tertantang dan lebih aktif selama proses pembelajaran. Selain menggunakan model pembelajaran yang variatif guru juga dapat menggunakan media pembelajaran sebagai variasi yaitu menggunakan Papan Putar, media Papan Putar cocok dipadukan dengan Model Team Games Tournament (TGT). Menurut penelitian yang dilakukan oleh Teguh Sumantoro (2013) mengenai "Pengembangan Perangkat Pembelajaran Metode Pembelajaran Kooperatif Tipe Teams Games Tournament (TGT) Menggunakan Media Permainan Ular Tangga Untuk Meningkatkan Hasil Belajar Siswa". Media permainan ular tangga ini dapat digunakan untuk meningkatkan motivasi belajar siswa, karena kegiatan belajar dapat menjadi lebih menarik dan mampu melibatkan seluruh siswa belajar secara aktif, sebab dalam media permainan ini terdapat aturan-aturan yang mengharuskan siswa aktif dalam memecahkan masalah yang ada. Oleh karena itu, Penggunaan media pembelajaran dimaksudkan agar peserta didik tertarik selama proses pembelajaran.

Penelitian ini telah dilaksanakan di kelas IV SDN Rejosari 03 dan SDN Rejosari 02 Kabupaten Semarang tahun ajaran 2018/2019 semester genap. Proses pembelajaran dilakukan dengan menggunakan model Team Games Tournament (TGT) berbantu media papan putar yang diterapkan di kelas eksperimen dan model konvensional diterapkan di kelas kontrol. Berdasarkan hasil evaluasi yang diberikan kepada peserta didik sebelum dan sesudah diberi perlakuan (treatment), dari analisis data dapat diketahui nilai rata - rata kelas eksperimen sebelum mendapat perlakukan diperoleh 66,36 setelah mendapat perlakuan diperoleh hasil 76,59. Hasil evaluasi yang diberikan kepada kelas kontrol pada saat pretest memperoleh rata - rata 61,82 sedangkan setelah diberi perlakuan nilai posttest diperoleh rata - rata 67,50 . Hal ini menunjukkan bahwa terjadi peningkatan prestasi belajar siswa pada kelas eksperimen lebih besar daripada kelas kontrol.

Berdasarkan hasil analisis data dapat disimpulkan bahwa peningkatan hasil rata rata nilai posttest pada kelas eksperimen dikarenakan pembelajaran menggunakan model pembelajaran Team Games Tournament (TGT) berbantu media papan putar, sehingga nilai rata - rata posttest kelas eksperimen lebih tinggi daripada nilai posttest kelas kontrol yaitu 76, 59 dibandingkan dengan nilai rata - rata kelas kontrol yaitu 67,50. Uji hipotesis yang dilakukan menggunakan uji t dengan rumus polled varian menggunakan data nilai posttest diperoleh thitung $=2,963$ dengan ttabel $=2,021$. Hal ini menunjukkan bahwa thitung $>$ ttabel yaitu 2,963 > 2,021. Maka dapat dikatakan bahwa pembelajaran yang menggunakan model pembelajaran Team Games Tournament (TGT) berbantu media papan putar efektif terhadap prestasi belajar siswa kelas IV SDN Rejosari 03 Kabupaten Semarang.

Hasil penelitian ini sejalan dengan penelitian Nuryani (2018) yang menunjukkan bahwa terjadi peningkatan hasil belajar siswa dengan menggunakan model pembelajaran Teams Game Tournament berbantu media Puzzle. Ada perbedaan hasil belajar IPS dengan menggunakan Model pembelajaran Teams Game Tournament berbantu media Puzzle kelas III SDN Sendangmulyo 02 Semarang. Penelitian Kusumadiputra (2017) menujukkan bahwa terdapat pengaruh yang signifikan dengan penerapan model pembeajaran Team Games Turnament terhadap hasi belajar TIK siswa kelas XI SMA Negeri 1 Sawan tahun ajaran 2015/2016 dibandingkan dengan siswa yang menggunakan model pembelajaran Learning Tournament maupun yang menggunakan model pembelajaran konvensional. Motivasi dan Respon siswa pada model pembelajaran Team Games Tournament lebih tinggi daripada model pembelajaran Learning Tournament.. Ini berarti, model pembelajaran Team Games 
Tournament lebih disenangi oleh siswa. Penelitian Hermayanti (2018) menyatakan bahwa model pembelajaran kooperatif tipe Team Games Tournament (TGT) berbantuan peta konsep berpengaruh signifikan terhadap hasil belajar IPA siswa kelas V di Gugus VI Kecamatan Sukasada Kabupaten Buleleng Tahun Pelajaran 2016/2017

\section{Simpulan dan Saran}

Berdasarkan hasil analisis dan perhitungan yang telah dilakukan menggunakan uji hipotesis paired sample $\mathrm{t}$ - test dengan rumus polled varian diketahui bahwa kelompok eksperimen $\mathrm{n} 1=22$ dengan rata - rata $(\bar{X} 1)$ Sebesar 76.59 . Sedangkan untuk kelas kontrol dengan n2 = 22 memperoleh rata - rata (X) sebesar 67.50 . Varian dari masing - masing kelompok yaitu varian keompok eksperimen (s_1^2) sebesar 57.696 dan untuk kelompok kontrol $\left(s \_2^{\wedge} 2\right)$ sebesar 149.432 serta thitung $=2.963$ dan ttabel $=2.021$ untuk taraf signifikan $5 \%$. Sehingga dapat disimpulkan bahwa thitung >ttabel , maka $\mathrm{HO}$ ditolak. Artinya model pemebalajaran model Team Games Tournamnet (TGT) berbantu media Papan Putar mata pelajaran tematik efektif terhadap prestasi belajar siswa kelas IV SDN Rejosari 03 Kabupaten Semarang.

\section{Daftar Pustaka}

Ahmadi dan Widodo.2013,Psikologi Belajar,Jakarta:PT.Rineka Cipta

Arikunto, Suharsimi. 2010. Prosedur Penelitian. Jakarta: PT Rineka Cipta.

Arikunto, Suharsimi. 2013. Dasar-Dasar Evaluasi Pendidikan. Jakarta : PT Rineka Cipta.

Arsyad,2014.Media Pembelajaran,Jakarta : PT.Raja Grafindo Persada

Azwar,2014.Reliabilitas dan Validitas,Yogyakarta : Pustaka Belajar.

Candra, Ni Made Yuni, Made Putra, I Ketut Ardana. 2017. PENGARUH MODEL PEMBELAJARAN KOOPERATIF TIPE TEAMS GAMES TOURNAMENT BERBANTUAN PETA KONSEP TERHADAP KOMPETENSI PENGETAHUAN IPA SISWA KELAS IV SD GUGUS LETDA MADE PUTRA. e-Journal PGSD Universitas Pendidikan Ganesha Mimbar PGSD Vol: 5 No: 2

Dewi, I. A. Kd. Novia Puspita. 2017. "Pengaruh Model Pembelajaran Kooperatif Tipe TGT Terhadap Hasil Belajar PKn Siswa Kelas V SD". e-Journal Mimbar PGSD Universitas Pendidikan Ganesha Jurusan PGSD, Vol5, No 2.

Hamdani. 2011. Dasar-Dasar Kependidikan. Bandung: CV Pustaka Setia.

Hermayanti, Putu, Made Sumantri, I Komang Sudarma. 2018. Pengaruh Model Pembelajaran Kooperatif Tipe Team Games Tournament Berbantuan Peta Konsep Terhadap Hasil Belajar IPA. Jurnal IImiah Sekolah Dasar Volume 2, Number 2, Tahun 2018, pp. 151-159 P-ISSN: 2579-3276 E-ISSN : 2549-6174 Open Access: ttps://ejournal.undiksha.ac.id/index.php/JISD/index

Jurnal.M Nur Rofiq.2017. pembelajaran kooperatif (cooperative learning) dalam pengajaran pendidikan agama islam

Jurnal.2017. Penerapan model pembelajaran kooperatif tipe TGT (Team Games Tournament) terhadap aktivitas dan Prestasi belajar pada tema cita citaku kelas IV SD Negeri jomblang 01 Semarang. Skripsi dipublish.Semarang 
Jurnal.Tria Agus Setyaningrum.2018. Keefektifan Model Pembelajaran Team Games Tournament (TGT) Berbantu media CD interaktif pada materi IPA Terhadap Motivasi belajar siswa kelas V SDN Pleburan 03 Semarang.Skripsi dipublish: Semarang

Kementerian Pendidikan Dan Kebudayaan Republik Indonesia 2018 tentang Dinamika Perkembangan Kurikulum 2013.

Kusumadiputra, Made Novta, Ketut Agustini, Gede Aditra Pradnyana. 2017. Study Komparatif Model Pembelajaran Team Games Tournament (TGT) dan Learning Tournament Terhadap Motivasi dan Hasil Belajar Teknologi Informasi dan Komunikasi (TIK) Siswa Kelas XI SMA. Jurnal Nasional Pendidikan Teknik Informatika (JANAPATI) Universitas Pendidikan Ganesha, Vol 6, No 1. Di akses melalui https://ejournal.undiksha.ac.id/index.php/janapati/article/view/9924

Marianti dan Ratnawati Susanto 2017. "Pengaruh Model Cooperative Learning Tipe Teams Games Tournament (TGT) terhadap Kecerdasan Interpersonal Pada Mata Pelajaran IPS". Jurnal IImiah Sekolah Dasar Vol.1 (4) pp. 260-269.

Nuryani, Siti, Henry Januar SaputraMei Fita Asri Untari. 2018. Keefektifan Model Pembelajaran Team Games Tournament (TGT) Dalam Pembelajaran IPS. International Journal of Elementary Education. Volume 2, Number 4, Tahun 2018, pp. 331-339. Di akses melalui https://ejournal.undiksha.ac.id/index.php/lJEE.

Purwandari, Amanda \& Dyah Tri Wahyuningtyas. 2017. "Eksperimen Model Pembelajaran Teams Games Tournament (TGT) Berbantuan Media Keranjang Biji-Bijian terhadap Hasil Belajar Materi Perkalian dan Pembagian Siswa Kelas II SDN Saptorenggo". Jurnal IImiah Sekolah Dasar. Vol.1 (3) pp. 163-170.

Rusman,2010.Model- model pembelajaran Mengembangkan Profesionalisme Guru,Jakarta : PT.Raja Grafindo Persada

Sadiman,2002.Media Pendidikan, pengertian, pengembangan dan pemanfaatannya. Jakarta : Sari Pustaka Teknologi Pendidikan

Salam, A., Hossain, A., \& Rahman, S. 2015. Effects of using Teams Games Tournaments (TGT) Cooperative Technique for Learning Mathematics in Secondary Schools of Bangladesh. Malaysian Online Journal of Educational Technology, Vol.3 No.3, Hal. 111.

Shoimin,2014.68 Model Pembelajaran Inovatif dalam Kurikulum 2013, Yogyakarta : Ar-Ruzz Media.

Suari, Mirah Marlia. 2008. "Penerapan Model Pembelajaran Kooperatif dengan Metode TGT (Teams Games Tournament) untuk Meningkatkan Hasil Belajar Siswa pada Mata Pelajaran Ekonomi di Kelas X-6 Semester 1 SMAN 2 Singaraja Tahun Ajaran 2008/2009". E-Jurnal Undiksha Vol 1 No 12008.

Sudimahayasa, Nyoman. 2015. "Penerapan Model Pembelajaran TGT Untuk Meningkatkan Hasil Belajar, Partisipasi, dan Sikap Siswa". Jurnal Pendidikan dan Pengajaran, Jilid 48, Nomor 1-3, April 2015, hlm. 45-53.

Sugiyono,2010.Metodelogi Penelitian Kuantitatif Kualitatif dan R\&D, Bandung : Alfabeta

Sugiyono,2015.Metodelogi Penelitian Kuantitatif Kualitatif dan R\&D, Bandung : Alfabeta. 
Susanna. 2017. Penerapan Teams Games Tournament (Tgt) Melalui Media Kartu Domino Pada Materi Minyak Bumi Siswa Kelas Xi Man 4 Aceh Besar. Lantanida Journal, Vol. 5 No. 2 (2017) 93-196

Hamdani. 2011. Dasar-Dasar Kependidikan. Bandung: CV Pustaka Setia.

Shoimin,2014.68 Model Pembelajaran Inovatif dalam Kurikulum 2013, Yogyakarta : Ar-Ruzz Media

Sugiyono,2010.Metodelogi Penelitian Kuantitatif Kualitatif dan R\&D, Bandung : Alfabeta

Sugiyono,2015.Metodelogi Penelitian Kuantitatif Kualitatif dan R\&D, Bandung : Alfabeta.

Tarigan, R. (2012). Pengaruh model pembelajaran kooperatif tipe Teams Games Tournament terhadap hasil belajar IPA Fisika di SMP Negeri 1 Percut Sei Tuan. Jurnal Penelitian Inovasi Pembelajaran Fisika. 4 (2), hlm. 50-55

Yudianto, Wisnu D., Kamin Sumardi, Ega T. Berman. 2014. MODEL PEMBELAJARAN TEAMS GAMES TOURNAMENT UNTUK MENINGKATKAN HASIL BELAJAR SISWA SMK . Journal of Mechanical Engineering Education, Vol.1, No.2. 